\title{
Leucocyte esterase-nitrite screening method for pyuria and bacteriuria
}

\author{
EGL WILKINS, JG RATCLIFFE, C ROBERTS \\ From the Regional Public Health Laboratory, Fazakerley Hospital, Liverpool
}

SUMMARY The value of the one minute leucocyte esterase-nitrite chemical strips as a screening procedure for detecting appreciable levels of pyuria and bacteriuria was assessed by comparison with microscopy and culture results. The likelihood that a negative leucocyte esterase result indicated $<10$ white cells/cu $\mathrm{mm}$ by microscopy (the negative predictive value), was $90 \cdot 1 \%$ and that a negative nitrite result indicated $<10^{5}$ organisms $/ \mathrm{ml}$ was $91.3 \%$. There were many false positive results with both tests, however, and the overall predictive value of a positive leucocyte esterase or nitrite test, or both, was low. The leucocyte esterase-nitrite strip was neither sufficiently sensitive nor specific enough to be used as a cost effective method for screening urines in the laboratory.

The established criteria and methods for diagnosing urinary tract infection have their drawbacks; poor correlation between the clinical and laboratory diagnosis; and difficulties in interpreting laboratory results. Dysuria, pyuria, and bacteriuria are the diagnostic features of infection. Dysuria without bacteriuria and asymptomatic bacteriuria often occur, however, and together with the many factors that can influence the bacterial and white cell counts-for example, collection, storage, and transport of specimens-attest to the problems of accurate diagnosis. ${ }^{12}$ The continuing emphasis on cost effectiveness and the increasing number of requests for the examination of urine have produced several rapid laboratory screening methods to help eliminate unnecessary examination by nicroscopy and culture. Since its introduction the leucocyte esterase-nitrite reagent strip has been used in laboratories with encouraging results to screen urines for the presence of pyuria and bacteriuria. ${ }^{3-8}$ The reagent strips have a role in hospital wards, outpatient clinics, and general practitioners' surgeries. As specimens of urine are an important element of our workload we examined the leucocyte esterase-nitrite test strip, together with other options, as a rapid screening method for detectable concentrations of pyuria and bacteriuria and then compared the results with our current system of culture and microscopy.

Accepted for publication 13 August 1985

\section{Material and methods}

A total of 903 urine samples from 147 men and 756 women in a district general hospital were examine $\mathbb{B}$ The collection and delivery of samples were done accordance with normal hospital practice, and no attempt was made to modify collection arrangements in the wards. Nearly all the samples were midstream specimens with a small number of specimens from catheters and bags. Undiluted uncentrifuged urine was used for all the tests, and specimens were either processed immediately on arrival in the laboratory or refrigerated at $4^{\circ} \mathrm{C}$ until processing could be performed (usually within one hour of receipt). Numbers of white cells were counted microscopically using a volumetric chamber count method (Kova slide with grid). A $0.005 \mathrm{ml}$ calibrated platinum loop was used to inoculate horse blood agar, which was incubated for 18-24 hours before being examined for discrete colonies. Quantitative bacterial counts were performed using Mast Bacteruritest filter strips inoculated by impression on to MacConkey agar and incubated for 18-24 hours. Colony forming units in the impression area were then compared with our stan-

Table 1 Comparison between microscopy and leucocyte esterase test in determining pyuria

\begin{tabular}{lll}
\hline $\begin{array}{l}\text { Leucocyte } \\
\text { esterase }\end{array}$ & Microscopy \\
\cline { 2 - 3 } test & $>10$ white cells/cu mm & $<10$ white cells/cu mm \\
\hline Positive & $210 \mathrm{a}>$ & $164 \mathrm{~b}>$ \\
Negative & $45 \mathrm{c}>$ & $410 \mathrm{~d}>$ \\
\hline
\end{tabular}


Table 2 Sensitivity, specificity, and predictive values (\%) of leucocyte esterase test in predicting levels of pyuria

\begin{tabular}{lllll}
\hline & Sensitivity & Specificity & Predictive value of & \\
\cline { 3 - 5 } & & & Positive test & Negative test \\
\hline $\begin{array}{llll}\text { Calculation }(\times 100) \\
\text { Index }(\%)\end{array}$ & $\mathrm{a} / \mathrm{a}+\mathrm{c}$ & $\mathrm{d} / \mathrm{d}+\mathrm{b}$ & $\mathrm{a} / \mathrm{a}+\mathrm{b}$ & $\mathrm{d} / \mathrm{d}+\mathrm{c}$ \\
\hline
\end{tabular}

The values for $\mathrm{a}, \mathrm{b}, \mathrm{c}$, and $\mathrm{d}$ are given in Table 1 .

dard curve for the bacterial count $/ \mathrm{ml}$. Only limited bacterial identification was undertaken by conventional means, unless contraindicated by epidemiological or other reasons.

For the purposes of this comparative study a clinically important level of pyuria was defined as $>10$ white cells/cu mm in uncentrifuged urine and that of bacteriuria as a pure or clearly predominant culture of $>10^{5}$ organisms $/ \mathrm{ml}$. Secondary organisms were regarded as unimportant if they occurred in counts of $<10^{4}$, and three or more organisms were regarded as contaminants.

Leucocyte esterase and nitrite activity were determined by dipping a Nephur test and leucocyte strip (Boehringer, Mannheim, West Germany) into urine for one second. Excess urine was drained off, and the colour reactions on the esterase and nitrite pads were compared with a reference colour chart at 60 seconds. Equivocal leucocyte esterase tests were assessed again at 120 seconds.

\section{Results}

Of the 903 urine specimens tested, $74(8 \cdot 2 \%)$ were judged to be contaminated and 829 specimens were subsequently evaluated. There was agreement in 210 specimens that gave positive white cell results by both microscopy and leucocyte esterase test, as well as $\mathbf{4 1 0}$ urines that gave negative white cell results by both methods (Table 1). These results were then applied to determine the sensitivity, specificity, and predictive values of the leucocyte esterase test screen $^{6}$ (Table 2).

On culture 702 had either no growth or $<10^{5}$ organisms/ml, while the remaining 127 specimens

Table 3 Isolates from patients with clinically important levels of bacteriuria

\begin{tabular}{lc}
\hline Isolates & No of patients \\
\hline Lactose fermenting coliforms & 103 \\
Proteus species & 9 \\
Faecal streptococci & 6 \\
Pseudomonas aeruginosa & 4 \\
Group B Streptococcus & 3 \\
Staphylococcus epidermidis & 1 \\
Staphylococcus aureus & 1 \\
Total & 127 \\
\hline
\end{tabular}

showed a clinically important level of bacteriuria (Table 3). Of these $127,80(63 \%)$ were positive by the nitrite test (Table 4). Table 5 shows the sensitivity, specificity, and predictive values of the nitrite strips in predicting clinically important bacteriuria.

Some authors who used the association between pyuria and bacteriuria to justify the use of the leucocyte esterase test as a predictor of important levels of bacteriuria reported favourable results. ${ }^{46}$ Although this association requires qualifications, we also examined this aspect of the combined test to see if it correlated with significant bacteriuria (Table 6).

When the sensitivity, specificity, and predictive values of the leucocyte esterase and nitrite tests were compared with the conventional methods either separately (Tables 2 and 5), or in combination (Table 6), the positive predictive value was poor for all the variables.

\section{Discussion}

Preliminary reports on the leucocyte esterase and nitrite tests used either separately or in combination showed that there were merits and limitations.

Leucocyte esterase activity is said to correlate closely with volumetric chamber counts and is specific for leucocytes, it does not require intact cells and is therefore not adversely affected by delay in analysis. ${ }^{9}$ It is also not influenced by bacteriuria, osmolality, $\mathrm{pH}$, or red cells, although heavy proteinuria may produce false negative results. Using 10 or more cells/cu $\mathrm{mm}$ to indicate a clinically important level of pyuria, we found the sensitivity of the esterase test was $82.4 \%$ with a specificity of $71 \cdot 4 \%$. Previous reports showed a similar sensitivity, although specificity was greater $(89 \cdot 8-97 \cdot 5 \%){ }^{35}$

The higher incidence of false positive results in this

Table 4 Comparison between culture and nitrite test in determining bacteriuria

\begin{tabular}{lll}
\hline Nitrite test & Culture \\
\cline { 2 - 3 } & $>10^{5}$ organisms $/$ ml & $<10^{5}$ organisms $/$ ml \\
\hline Positive & $80 \mathrm{a}$ & $209 \mathrm{~b}$ \\
Negative & $47 \mathrm{c}$ & $493 \mathrm{~d}$ \\
\hline
\end{tabular}


Table 5 Sensitivity, specificity, and predictive values (\%) of the nitrite test in predicting significant bacteriuria

\begin{tabular}{|c|c|c|c|c|}
\hline & \multirow[t]{2}{*}{ Sensitivity } & \multirow[t]{2}{*}{ Specificity } & \multicolumn{2}{|c|}{ Predictive value of } \\
\hline & & & Positive test & Negative test \\
\hline $\begin{array}{l}\text { Calculation }(\times 100) \\
\text { Index }(\%)\end{array}$ & $\begin{array}{l}a / a+c \\
63 \cdot 0\end{array}$ & $\underset{70 \cdot 2}{\mathrm{~d} / \mathrm{d}}+\mathrm{b}$ & $\underset{27 \cdot 7}{a / a}+b$ & $\begin{array}{l}\mathrm{d} / \mathrm{d}+\mathrm{c} \\
91 \cdot 3\end{array}$ \\
\hline
\end{tabular}

The values for $a, b, c$, and $d$ are given in Table 4 .

Table 6 Sensitivity, specificity, and predictive values (\%) of various tests in predicting significant bacteriuria

\begin{tabular}{lllll}
\hline Tests & Sensitivity & Specificity & Predictive value of \\
\cline { 3 - 5 } & & & Positive test & Negative test \\
\hline Microscopy > 10 white cells/cu mm & $70 \cdot 1$ & $76 \cdot 4$ & 34.9 & $93 \cdot 4$ \\
Nitrite or leucocyte esterase positive, or both & $84 \cdot 3$ & $50 \cdot 3$ & 23.5 & 94.6 \\
Nitrite and leucocyte esterase positive & $56 \cdot 7$ & $80 \cdot 8$ & 34.8 & $91 \cdot 2$ \\
\hline
\end{tabular}

study may have been partly due to difficulties in reading the esterase colour change, which was subtle at times. Equivocal reactions at 60 seconds were assessed again at 120 seconds when any perceptible colour change was regarded as positive. Of the 164 false positive results, nearly two thirds were due to borderline positive leucocyte esterase readings, and this may reflect our low threshold for recording a positive result. A reflectance meter, which is available for reading this test, would have given us more objective results (Uroton, Bio-Dynamics). Due to the ability of the test to identify lysed white cells, however, it is clearly difficult to assess its efficiency by comparison with the results of the microscopy test; of the two tests, the esterase may give the more accurate and representative result. Even if we assume that the leucocyte esterase activity correlates closely with the microscopical results, pyuria alone is an unreliable indicator of urinary tract infection. ${ }^{10}$

Similarly, the nitrite test is recognised as an insensitive screening test for detecting bacteriuria, ${ }^{711}$ and this was confirmed in our study (Tables 4 and 5). False negative results are usually related to insufficient nitrate in the urine, non-nitrite producing organisms, or inadequate contact time between the organisms that can reduce nitrate and the urinary nitrate. Despite the relative insensitivity of each test when they were examined separately, Smalley and Dittman showed a sensitivity of $82.5 \%$ and a specificity of $98.4 \%$ using the combined leucocyte esterase and nitrite strip, and either, or both variables as an indicator of the presence of clinically important bacteriuria. $^{6}$ These results contradicted ours (Table 6); although the sensitivity of the leucocyte esterase and nitrite test $(84.3 \%$ ) was similar to that previously reported (82.5-86.8\%), ${ }^{6-8}$ false positive results were common, and the likelihood of a patient with a positive leucocyte esterase or nitrite test, result, or both, having a clinically important level of bacteriuria (the positive predictive value) was only $23.5 \%$. As a screening test this is unacceptable, unless there is also very high sensitivity. With a sensitivity of only $84.3 \%$, we found that the leucocyte esterase and nitrite test was an inefficient method for screening. The predictive value of a test depends on the prevalence of disease, so that if there had been a lower prevalence of urinary tract infection among the populatione screened the positive predictive value would have been even less, assuming the same sensitivity ande specificity.

To conclude, we found the leucocyte esterase nitrite strip was neither sufficiently sensitive nor specific enough to be used as a cost effective method for screening out negative urines in the laboratory. This contrasted with previous reports. ${ }^{6-8}$ In addition, a positive result for either variable was not specific enough for predicting the presence of a clinically important level of bacteriuria, and therefore would not be sufficient evidence for diagnosing urinary tract infection and starting treatment.

\section{References}

${ }^{1}$ Kass EH. Should bacteriuria be treated? An interpretative essay. In: Brumfitt W, Hamilton-Miller JMJ, eds. A clinical approach to progress in infectious diseases. Oxford: Oxford University Press, 1983:78-95.

${ }^{2}$ Maskell R. Urinary tract infection. In: Phillips I, ed. Current topics in infection series. London: Edward Arnold, 1982:21-41.

${ }^{3}$ Gelbart SM, Chen WT, Reid R. Clinical trial of one minute leucocyte test strip for detecting urinary tract infection. Abstracts of the Annual Meeting of the American Society for Microbiology 1983:313.

${ }^{4}$ Perry JL, Matthews JS, Weesner DE. Evaluation of leucocyte esterase activity as a rapid screening technique for bacteriuria. $J$ Clin Microbiol 1982;15:852-4.

${ }^{5}$ Smalley DL, Bryan JA. Comparative evaluation of the biochemical and microscopic urinalysis. Am J Med Technol 1983;49:237-9.

${ }^{6}$ Smalley DL, Dittman AN. Use of leukocyte esterase-nitrate activ- 
ity as predictive assays of significant bacteriuria. $J$ Clin Microbiol 1983;18:1256-7.

${ }^{7}$ Wenk RE, Dutta D, Rudert J, Kim Y, Steinhagen C. Sediment microscopy, nitrituria, and leukocyte esterasuria as predictors of significant bacteriuria. Journal of Clinical Laboratory Automation 1982;2:117-21.

${ }^{8}$ Wise KA, Grammens GL, Sagert LA. The use of urinary leukocyte esterase and nitrite as an aid in predicting urine culture results. Abstracts of the Annual Meeting of the American Society for Microbiology 1983:313.
${ }^{9}$ Kusumi RK, Grover PJ, Kunin CM, Rapid detection of pyuria by leukocyte esterase activity. JAMA 1981;245:1653-5.

${ }^{10}$ Robins DG, White RHR, Rogers KB, Osman MS. Urine microscopy as an aid to detection of bacteriuria. Lancet 1975;i:476-8.

${ }^{11}$ Monte-verde D, Nosanchirk JS. The sensitivity and specificity of nitrite testing for bacteriuria. Lab Med 1981;12:755-7.

Requests for reprints to: Dr C Roberts, Consultant Medical Microbiologist, Public Health Laboratory, Fazakerley Hospital, Lower Lane, Liverpool L9 7AL, England. 